\title{
Attitudes and the (dis)continuity between memory and imagination*
}

\author{
André Sant'Anna \\ Washington University in St. Louis, St. Louis, United States \\ E-mail: andrer@wustl.edu \\ Recibido: 30 de octubre de 2020 | Aceptado: 16 de marzo de 2021 \\ https://doi.org/10.17533/udea.ef.n64a04
}

\begin{abstract}
The current dispute between causalists and simulationists in philosophy of memory has led to opposing attempts to characterize the relationship between memory and imagination. In a recent overview of this debate, Perrin and Michaelian (2017) have suggested that the dispute over the (dis)continuity between memory and imagination boils down to the question of whether a causal connection to a past event is necessary for remembering. By developing an argument based on an analogy to perception, I argue that this dispute should instead be viewed as a dispute about the nature of the attitudes involved in remembering and imagining. The focus on attitudes, rather than on causal connections, suggests a new way of conceiving of the relationship between memory and imagination that has been overlooked in recent philosophy of memory.
\end{abstract}

Keywords: memory, imagination, causal theory, simulation theory, continuism, discontinuism

* Much of the work on this paper was done when I was a postdoctoral researcher at the Centre for Philosophy of Memory at the Université Grenoble Alpes and was supported by the French National Research Agency in the framework of the "Investissements d'avenir" program (ANR-15-IDEX-02).

\section{Cómo citar este artículo}

Sant'Anna, A. (2021). Attitudes and the (dis)continuity between memory and imagination. Estudios de Filosofía, 64, 73-93. https://doi.org/10.17533/udea.ef.n64a04

\section{OPEN ACCESS}

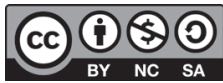

Estud.filos n. ${ }^{0}$ 64. Julio-diciembre de 2021 | pp. 73-93 | Universidad de Antioquia | ISSN 0121-3628 | ISSN-e 2256-358X 


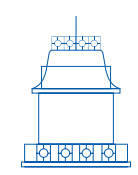

ARTÍCULO

DE INVESTIGACIÓN

\section{Las actitudes y la (dis)continuidad entre la memoria y la imaginación}

Resumen: La disputa actual entre causalistas y simulacionistas en filosofía de la memoria ha llevado a intentos opuestos de caracterizar la relación entre memoria e imaginación. En una revisión reciente de este debate, Perrin y Michaelian (2017) han sugerido que la disputa sobre la (dis)continuidad entre la memoria y la imaginación se reduce a la cuestión de si para recordar es necesaria una conexión causal con un evento pasado. Al desarrollar un argumento basado en una analogía con la percepción, sostengo que esta disputa debería verse como una disputa sobre la naturaleza de las actitudes involucradas en recordar e imaginar. El enfoque en las actitudes, más que en las conexiones causales, sugiere una nueva forma de concebir la relación entre la memoria y la imaginación que se ha pasado por alto en la filosofía reciente de la memoria.

Palabras clave: memoria, imaginación, teoría causal, teoría de la simulacion, continuismo, discontinuismo

\section{André Sant'Anna}

Postdoctoral Researcher in the Department of Philosophy and the Philosophy-Neuroscience-Psychology Program at Washington University in St. Louis.

ORCID: 0000-0002-2239-7243 


\section{Introduction}

The current dispute between causalism and simulationism in philosophy of memory has led to opposing attempts to characterize the relationship between memory and imagination. According to causalists, memory is discontinuous with imagination, for a causal connection is necessary only for remembering. According to simulationists, memory is continuous with imagination, and for this reason, a causal connection is not necessary for remembering. This has led Perrin \& Michaelian (2017) to suggest that the dispute over the (dis)continuity between memory and imagination boils down to the question of whether a causal connection is necessary for remembering. By developing an argument based on an analogy to perception, I propose that, given the commitment by causalists and simulationists to a representationalist approach to mental states, it is wrong to frame the dispute over the (dis)continuity between memory and imagination in terms of the necessity of a causal connection for remembering. Instead, I propose that it should be viewed as dispute about the nature of the attitudes involved in remembering and imagining. One crucial implication of this way of looking at things is, I will suggest, that philosophers of memory should distinguish between two related but separate debates: namely, the debate over whether a causal connection is necessary for remembering, on the one hand, and the debate over whether memory and imagination are continuous, on the other hand.

I proceed as follows: Section 2 introduces and discusses the causal theory, the simulation theory, and how they conceive of the relationship between memory and imagination. Section 3 draws an analogy to perception to argue that it is wrong to view the requirement for the presence of a causal connection in remembering as fundamental to establishing the (dis)continuity between memory and imagination. Section 4 discusses how my proposal relates to recent attempts to intervene in the (dis)continuism debate. Section 5 concludes by responding to potential objections to the analogy to perception argument.

\section{2 (Dis)continuism and the necessity of a causal connection for remembering}

Is a causal connection necessary for remembering? Two influential theories have been developed in response to this question. The causal theory of memory, or simply causalism, says that remembering occurs only when memory is appropriately caused by a past perceptual experience. ' While there is room to dispute what it is for a past

1 For different versions of the causal theory, see Martin \& Deutscher (1966); Bernecker (2010); Debus (2010); Michaelian (2011); Robins (2016); Werning (2020) 
event or experience to appropriately cause a current mental state, one popular strategy has been to appeal to the presence of a memory trace, ${ }^{2}$ or a brain state that encodes and stores information at the time of experience and that is later retrieved to cause memories of those events. Thus, causalists have proposed that a causal connection is appropriate when it takes place by means of a memory trace connecting a particular past event to a current representation of it.

The causal theory has been dominant in philosophy for multiple reasons. ${ }^{3}$ One of these reasons, which will be the focus of this paper, is that it captures an important metaphysical intuition about remembering: that is, that it differs in kind from imagining. A clear illustration is provided by the notorious painter example discussed by Martin \& Deutscher (1966, pp. 167-168). In this example, we are asked to imagine the case of a painter who, as a result of being asked to paint an imagined scene, produces a painting of a farmyard that he genuinely believes to be imagined. However, when his parents see the painting, they recognize it as being a very accurate representation of a scene that the painter saw once as a child, thus suggesting that he is actually remembering that scene. The question that this example raises is whether the painter is remembering or imagining the scene. Setting aside the issue of whether the painter needs to believe that he is remembering in order to genuinely remember, ${ }^{4}$ the causal theory offers a simple way to settle the issue: If there is an appropriate causal connection between the painter's current mental representation of the farmyard and his previous experience of it, the representation will count as case of remembering; in contrast, if such a causal connection is missing, the representation will count as a case of imagining. Thus, the presence of a causal connection serves to differentiate between memory and imagination, considered as kinds of mental states. In other words, it postulates a discontinuity between them. ${ }^{5}$

The dominant status of the causal theory has, however, been questioned recently. The second theory that attempts to answer the question of whether a causal connection is necessary for remembering, the simulation theory, or simply simulationism, proposes that remembering is just a form of imagining the past. ${ }^{6}$ Recently developed in more detail by Michaelian (2016b), the simulation theory proposes that "[remembering] is not

2 Martin and Deutscher (1966) were the first to argue for this idea in the recent philosophy of memory literature. Despite the popularity of the causal theory, and despite being central for all subsequent versions of the theory (see Michaelian \& Robins, 2018, for review), the idea of a memory trace has been the object of many criticisms. See Sutton (1998, ch. 16) for discussion; see also De Brigard (2014b); Robins (2017).

3 For a helpful discussion of the causal theory and its influence on subsequent philosophical theorizing, see Michaelian and Robins (2018).

4 See Debus (2010) and Fernández (2018) for arguments for the necessity of belief for remembering.

5 See Debus (2014); Perrin (2016); Michaelian (2016a) for discussion.

6 For the most influential exposition of the simulation theory, see Michaelian (2016b). For alternative formulations, see De Brigard (2014a) and Shanton and Goldman (2010). For my purposes, I will focus on Michaelian's version only. See also Hopkins (2018) for a view where remembering is viewed as a form of imagining, but that does is not committed to simulationism. 
different in kind from other episodic constructive processes" (p. 103); thus "[w]hat it is for a subject to remember [...] is for him to imagine an episode belonging to his personal past" (p. 111). The motivation for the simulation theory comes from recent research on mental time travel. ${ }^{7}$ According to this body of research, (episodic) memory and (episodic) imagination are just two specific occurrences of a more general cognitive capacity that we have for mental time travel in subjective time: while remembering is the specific ability we have to mentally travel into past subjective time, so as to "re-live" or "re-experience" an event, imagining corresponds to the specific ability we have to mentally travel into future subjective time, so as to simulate the experience of a possible event. ${ }^{8}$

The idea that remembering and imagining are two specific occurrences of a more general cognitive capacity for mental time travel has motivated further empirical studies on their relationship, which has reinforced the initial suggestion that the two are closely intertwined. Perhaps the most significant results come from neuroimaging studies, which have revealed a strong overlap of brain regions associated with memory and mental time travel into the future. ${ }^{9}$ Building on this and other results, the simulation theory suggests that remembering and imagining are continuous; that is, that at the most fundamental level, they are mental states of the same kind..$^{10}$ The continuity between memory and imagination motivates the simulationist argument against the necessity of a causal connection for remembering. According to simulationists, given that mental time travel research implies that memory and imagination are mental states of the same kind, and given that imagination does not require a causal connection to what is imagined, it follows that a causal connection is not necessary for remembering. ${ }^{11}$

The current dispute between causalists and simulationists over the (dis)continuity between memory and imagination allows us to identify an important assumption made by both causalists and simulationists: namely, that if a causal connection is necessary for memory, then memory and imagination are mental states of different kinds. ${ }^{12}$ Let us call this the if-causation-then-discontinuity claim (ICTD). ICTD has been at the basis of the disagreement between causalists and simulationists over the (dis)continuity of memory and imagination. On the one hand, causalists rely on ICTD to propose a modus ponens argument for discontinuism. Following the causal theory, they assert

\footnotetext{
7 See Perrin and Michaelian (2017) for a review. See also Sant'Anna et. al. (2020).

8 See Tulving $(1993 ; 2002 ; 2005)$.

9 See Addis (2018; 2020); Addis et al. (2007); Schacter et al. (2007; 2012). See Perrin and Michaelian (2017) for a more detailed philosophical discussion.

10 See Michaelian (2016b;a); Michaelian et al. (2020), Sant'Anna (2020), Sant'Anna et. al. (2020)

11 The attempt to show that memory and imagination are continuous is not the only motivation that leads Michaelian to deny that a causal connection is necessary for remembering. Another equally important reason is the possibility of there being memory representations that are fully accurate but that are not causally connected to the original events-e.g. memories whose contents are derived from testimony or memories whose contents are derived from causal connections to events other than the event remembered. See Michaelian (2016b, ch. 6) for discussion.

12 See Perrin and Michaelian (2017) and Michaelian et. al. (2020) for explicit endorsements of this idea.
} 
the necessity of a causal connection for memory. This claim, in conjunction with ICTD, allows for the conclusion that memory and imagination are mental states of different kinds. On the other hand, simulationists rely on ICTD to propose a modus tollens argument for continuism. Following the simulation theory, they note that it is not the case that memory and imagination are mental states of different kinds. Combined with ICTD, this claim allows for the conclusion that a causal connection is not necessary for remembering. The problem with how this debate is structured is, however, that no explicit argument has been given for ICTD. Rather, this is an assumption made by both causalists and simulationists. In the next section, I argue that ICTD is false, or that the dispute over the (dis)continuity between remembering and imagining should not be about the necessity of a causal connection for remembering.

\section{Memory and imagination as representational states}

Despite disagreeing about whether memory and imagination are (dis)continuous, causalists and simulationists alike are committed to the more general idea that they are representational states, or simply to representationalism about memory and imagination. In his main discussion of the simulation theory, Michaelian (2016b) speaks explicitly of memory and imagination as representational states. Similarly, the original version of the causal theory developed by Martin and Deutscher (1966) and subsequent developments of it clearly suggest a commitment to some form of representationalism about memory. ${ }^{13}$ Furthermore, while philosophers of imagination have disputed the nature of the content of multiple forms of imagination, ${ }^{14}$ most of them agree that different imaginative states are fundamentally representational states. As Liao \& Gendler (2019) put it, to imagine "is to represent without aiming at things as they actually, presently, and subjectively are" (my emphasis; see also Currie \& Ravenscroft, 2002). Representationalism is, to put it differently, a widespread assumption in both the memory literature and the imagination literature, with very few people questioning the view. ${ }^{15}$

In what follows, I shall argue that, if representationalism is true, then the question about whether memory and imagination are (dis)continuous does not boil down to the necessity of a causal connection for remembering. Let me begin by defining representationalism more precisely. According to representationalism conceived in its most general form, what makes a mental state an occurrence of a certain kind is the attitude that one holds towards a content -e.g., a belief is characterized by an attitude of believing (understood as having a mind-to-world direction of fit) towards a certain

\footnotetext{
13 See Robins (2016) and Michaelian and Robins (2018) for discussion.

14 See, e.g., Nanay (2015); Langland-Hassan (2015).

15 See, however, Debus (2008); Hutto and Myin (2017).
} 
content, a desire is characterized by an attitude of desiring (understood as having a world-to-mind direction of fit) towards a content, and so on (Fodor, 1978). ${ }^{16}$ Thus, it follows that, if memory and imagination are understood as representational states, they too should be characterized in terms of the type of attitudes that is involved in each. The crucial question for any representationalist theory of memory and imagination is thus that of explaining the nature of these attitudes. Since, however, it is not my goal to defend representationalism, I shall leave this question aside.

What matters for my purposes is that the commitment to representationalism by both causalists and simulationists makes it clear that the question about the (dis)continuity between memory and imagination is not about the necessity of a causal connection for remembering, but rather about the nature of the attitudes involved in remembering and imagining. On the one hand, the causalist (and hence the discontinuist) will triumph if the attitude involved in remembering turns out to be different from the attitude involved in imagining. On the other hand, the simulationist (and hence the continuist) will triumph if the attitude involved in remembering turns out to be the same as the attitude involved in imagining. Whether or not a causal connection is necessary for remembering is orthogonal to settling this issue. ${ }^{17}$

To further motivate this point, considering an analogy to representationalist approaches to perception will help. One central question in recent philosophy of perception is whether veridical and non-veridical experiences are mental states of the same kind. Representationalists have answered this question in a positive manner. ${ }^{18}$ According to them, because veridical and non-veridical experiences represent the world in the same way -that is, because they involve the same attitude towards contents- they are mental states of the same kind. They differ only in terms of whether their contents are satisfied. What it means to say that a content is satisfied by the world is a matter of controversy, but one natural way to understand this idea is to say that a particular object satisfies a perceptual experience, and hence makes it a veridical occurrence, when it causes the experience in an appropriate way. Thus, when I have a visual experience as of a cat across the street, this experience will be veridical only if it is caused by a cat that is across the street. ${ }^{19}$ This allows representationalists to consistently hold on

16 It should be noted that the suggestion here is not, logically speaking, that we define the relevant attitudes in terms of the mental states they are intended to be a characterization of-e.g., that we define the attitude of believing in terms of what a belief is. In other words, representationalism is not engaged in circular reasoning here. Instead, to use belief as an example, the suggestion is that a belief is defined by an attitude of a certain type $\phi$, which is characterized by such-and-such properties, and because $\phi$ is characteristic of mental states that we ordinarily refer to as beliefs, we refer to $\phi$ as the attitude of believing. Thanks to an anonymous referee for calling my attention to this issue.

17 One may object here that it is not true that, in the case of remembering in particular, the presence of a causal connection is not necessary to characterize the attitude of remembering. I respond to this objection in more detail in Section 5.2 .

18 See, e.g., Bryne (2001; 2009); Schellenberg (2010); Searle (1983); Siegel (2010); Tye (2000).

19 A key issue here is whether the requirement for a causal connection to individuate a veridical experience as such -call this the individuation claim - requires that we represent the experience as being caused by the thing represented 
to the claim that a causal connection is necessary, albeit not sufficient, for veridical experiences, while still maintaining that veridical and non-veridical experiences are mental states of the same kind. Otherwise put, the necessity of a causal connection for veridical experiences does not imply a fundamental separation between veridical and non-veridical experiences.

I want to suggest that a similar approach is available to understand the relationship between memory and imagination. That is, just like in perception, where the requirement for a causal connection for veridical experiences does not imply a fundamental separation between veridical and non-veridical experiences, in the case of memory and imagination too, the requirement for a causal connection for remembering does not imply a fundamental separation between memory and imagination. Once representationalism is accepted as a starting point, it becomes clear that there is no incompatibility between the two. This argument, which I call the analogy to perception argument, can be laid out as follows:

\section{(The Analogy to Perception Argument)}

(P1) If representationalism is true of memory and imagination, then the requirement for a causal connection for remembering, but not for imagining, only poses a non-fundamental difference between them.

(P2) Representationalism is true of memory and imagination.

(C) The requirement for a causal connection in remembering, but not in imagining, only poses a non-fundamental difference between them.

As I argued above, (P1) reflects a more general principle of representationalism, namely, that if two potentially distinct mental states -e.g., veridical and non-veridical experiences- involve the same attitude towards contents, then they are mental states of the same kind. That a causal connection is only necessary for one of them only reflects a non-fundamental difference. (P2), in contrast, reflects the widespread theoretical assumption made by most philosophers of memory and philosophers of imagination discussed previously. ${ }^{20}$ Thus, once (P1) and (P2) are in place, it follows that (C) the requirement for a causal connection in remembering, but not in imagining, only poses a non-fundamental difference between them.

\footnotetext{
-call this the representation claim. While some, most notably Searle (1983), have answered this question positively, others have argued that the individuation claim can be secured without committing to the representation claim -see, e.g., Burge (1991); Soteriou (2000). For my purposes in this paper, I do not need to commit to any of these views.

20 I do not mean to suggest here that the widespread acceptance of (P2) by philosophers of memory and philosophers of imagination alike provides a reason for endorsing it. It may be, after all, that the assumption is wrong despite being widespread. The suggestion is, instead, that given its widespread acceptance, in particular by causalists and simulationists in the memory literature, and given the truth of (P1), (C) inevitably follows.
} 
Despite establishing that the requirement for a causal connection for remembering does not imply a discontinuity between memory and imagination, it is important to note that the analogy to perception argument should be viewed neither as an argument for or against causalism, nor as an argument for or against simulationism. The argument is neutral as to whether a causal connection is necessary for remembering (causalism), as well as to whether memory and imagination are mental states of the same kind (simulationism). All it says is that, given a shared assumption between simulationists and causalists -namely, representationalism - the question of whether memory and imagination are mental states of the same kind should be a question about the nature of the attitudes involved in remembering and imagining. The analogy to perception thus renders false the ICTD claim introduced in Section 2.

Furthermore, a more general implication of the analogy to perception argument is that philosophers of memory should distinguish between two related but separate debates: namely, the debate over whether a causal connection is necessary for remembering, on the one hand, and the debate over whether memory and imagination are continuous, on the other hand. While, insofar as the current philosophy of memory literature is concerned, the latter has sprung out of the former, they concern different questions pertaining to the nature of remembering and imagining. The tendency to conflate them, exemplified by Perrin \& Michaelian's (2017) proposal, overlooks important theoretical possibilities. In particular, once we distinguish between these two debates, a causalist-continuist view of memory becomes a real possibility. Whether such a view can be properly motivated is, of course, a question that is beyond my scope here, but it is certainly one that should be explored in future works on the subject.

\section{Attitudes and the (dis)continuism debate}

The suggestion that the (dis)continuism debate should be settled by considering the relationship between the attitudes of remembering and imagining has been echoed in recent work on the subject. For instance, Robins (2020) has recently argued that the attitude of 'seeming to remember', which she takes to be characteristic of occurrences of successful and unsuccessful remembering alike, and which involves entertaining a content as being past and as having happened, is clearly distinct from the attitude of imagining. The latter, she argues, involves entertaining a content as being fictional or possible (Van Leeuwen, 2013), thus suggesting that remembering and imagining are discontinuous. In a similar vein, Munro (2020) has argued that remembering is discontinuous with what he calls "hypothetical imagining" because they involve different attitudes towards contents. Unlike Robins (2020), though, Munro thinks that there is at least one type of imagining that is continuous with remembering -namely, what he calls 'actuality-oriented imagining', or situations in which one imagines actual 
scenarios, such as imagining the layout of a restaurant where one is going to dine. Crucially, Munro's strategy for defending this view is that of showing that remembering and actuality-oriented imagining involve attitudes of a very similar type. Thus, despite their differences, these two attempts share a more general motivation to resolve the (dis)continuism debate by offering characterizations of the attitudes of remembering and imagining, and as such, they come in support of the claim defended in this paper.

One dissenting proposal has, however, been advanced by Langland-Hassan (2021), which might cast doubt on the main claim I am defending here. According to LanglandHassan, it is wrong to view the (dis)continuism debate as a debate about attitudes. Instead, he argues that it should be viewed as a controversy over whether remembering is an instance of what has been called 'constructive imagining' (Van Leeuwen, 2013). The reason we should refrain from talking about attitudes, Langland-Hassan adds, is that continuists (and here he has the simulationist in mind) will happily accept the claim that memory and imagination clearly involve different attitudes. The argument in support of this claim appeals to Michaelian's (2016) claim that one of the conditions for remembering to happen is that it is produced by a reliably functioning episodic construction system that 'aims' at representing an event from one's personal past. This condition, Langland-Hassan argues, places unique epistemic constraints on remembering that do not hold for imagining. As he puts it, "[t]o say that the episodic construction system "aims at" an episode from one's actual personal past is to say that its products are in epistemic need of revision when that aim isn't met -viz., when the episodic memory does not accurately represent an episode from one's actual personal past" (Langland-Hassan, 2021, p. 237). Thus, since the same is not true of imagination, it follows that the attitudes of remembering and imagining are of different types.

As it stands, there are at least two difficulties with this argument. A first difficulty is that the simulationist view, at least as formulated by Michaelian (2016), does not require that the episodic construction system be successful in achieving its goal of representing an event from one's personal past for its outputs to count as occurrences of remembering. All that needs to be the case is, first, that the episodic construction system is functioning reliably and, second, that it has the 'aim' of representing an event from one's personal past, although it may well fail to do so. In other words, the requirement is that the episodic construction system has the relevant aim, and not that it succeeds in achieving that aim. That such is the case becomes clear when we consider the fact that Michaelian (2016, pp. 68-70) outright rejects a factive conception of remembering, which he takes to be incompatible with the naturalistic outlook on which the simulation view is based.

The reason this creates a problem for Langland-Hassan's proposal is that a similar way of talking of 'aims' could be proposed in an attempt to further specify when the episodic construction system is engaged in representing hypothetical and/ or future events. Consider future-oriented episodic imagining. It could be argued that one successfully imagines when the relevant representation is produced by a 
reliably functioning episodic construction system and when the system has the aim of representing an event in one's possible personal future. Likewise, consider pastoriented counterfactual imagining. It could be argued that one successfully imagines a past counterfactual scenario when the relevant representation is produced by a reliably functioning episodic construction system and when the system has the aim of representing an event in one's counterfactual personal past. In both cases, what matters is, just like in the case of remembering, that the system succeeds in having the relevant aim, and not that it succeeds in actually representing possible future or past counterfactual events. Now, once we interpret the requirement in question in this way, it is no longer clear whether, for the simulationist, the epistemic constraints placed on remembering differ in nature from the epistemic constraints placed on imagining. For what it takes for the system to succeed in all those cases is simply for it to have the goal of representing events as being a certain way.

The second, and related, difficulty faced by Langland-Hassan's proposal is that not only is it not clear that simulationists will readily endorse the idea that memory and imagining involve attitudes of different types, it is also not clear whether causalists would take that as a starting point. To see the point, consider again the painter case discussed above. If it is true that causalists readily accept that the attitude of remembering is different from the attitude of imagining, then the issue over whether the painter is remembering would easily be settled against them, for the painter is clearly entertaining a content as possible or fictional. Thus, it is hard to see how there would even be a question as to whether the painter is remembering if causalists took the attitude of remembering to be clearly distinct from the attitude of imagining. So, it may be that not even causalists would be convinced, at least prima facie, by the thought that the attitudes of remembering and imagining are clearly different. This, I submit, shows that the idea that the (dis)continuism debate has to do with what the attitudes of remembering and imagining are cannot be as easily dismissed as Langland-Hassan (2021) suggests.

\section{Objections}

In this final section, I will consider a few potential objections to the analogy to perception argument and argue that none of them are successful.

\subsection{Representationalism and discontinuism}

A first objection is that if the analogy to perception argument is right, then, given that it is obviously true that remembering and imagining involve different attitudes towards contents, in the same way that it is obviously true that remembering and perceiving 
involve different attitudes towards contents, it follows that discontinuism is the case. And this undermines the intended neutrality of the argument, for it is best viewed as an argument for causalism or discontinuism.

To see why this is not the case, consider the painter case discussed in Section 2. The fact that we are willing to accept that the painter may be remembering despite taking himself to be imagining a farmyard scene suggests that at least some occurrences of remembering play the same cognitive role as occurrences of imagining. Thus, as long as their contents are the same, it follows that they involve the same attitudes. ${ }^{21}$ Admittedly, this only establishes that some occurrences of imagining and some occurrences of remembering involve the same attitudes towards contents. One may argue, however, that there are occurrences of imagining that clearly play distinctive cognitive roles from occurrences of remembering. While this is true, it does not follow that the dispute is settled in favor of discontinuism. For these differences could, at least in principle, be explained in terms of remembering and imagining typically (although not necessarily) involving different contents -e.g., remembered events are typically represented as actual and imagined events are typically represented as possible. This would still be compatible with the idea that remembering and imagining involve the same attitudes, and hence compatible with continuism.

One clarification here is that I am not claiming that causalists themselves think that remembering and imagining are attitudes of the same kind. The claim is rather that, as long as we are speaking of attitudes, making sense of the painter case in the way that it has been usually conceived of in recent discussions requires acknowledging that some occurrences of remembering can involve the attitude of imagining. Otherwise, it is not clear why we should say that the painter remembers despite his mental state clearly involving an attitude of imagining -that is, despite him taking himself to be imagining the farmyard scene. ${ }^{22}$

To further motivate this point, consider an analogy to beliefs and desires. If we define beliefs and desires in terms of their attitudes, then it would be odd to say that it is possible for one to believe that $p$, but mistakenly take oneself to desire that $p$. If, in the case in question, $p$ plays the cognitive role of desiring -i.e., one expects $p$ to obtain, etc.- then it looks like one has a mental state of desiring that $p$ and not one of believing that $p$. On an attitude view of mental states, it would only be possible for one to believe that $p$ but mistakenly take oneself to desire that $p$ if the attitude of believing and the attitude of desiring were the same. The argument I am putting forward in connection

21 One may object here by saying that, if representationalism is true, then it cannot be the case that the painter is imagining, for he holds an attitude of remembering towards a content. In response, this only follows if discontinuism is accepted as a starting point, that is, if the attitude of remembering and the attitude of imagining are taken to be fundamentally different. However, on a continuist framework, this would not be problematic, for the attitude of remembering is just the attitude of imagining. Thus, it is not the case that representationalism necessarily conflicts with our intuitions in those cases.

Thanks to an anonymous referee for suggesting that I clarify this point. 
to memory and imagination is similar: on an attitude view of mental states, it would only be possible for one to remember that $p$ but mistakenly take oneself to imagine that $p$-this is what happens in the painter case- if the attitude of remembering and the attitude of imagining were the same. So, again, conceiving of the dispute between continuism and discontinuism in terms of attitudes does not straightforwardly settle the debate in favor of discontinuism.

\subsection{Attitudes and causal connections}

A second objection is that the analogy to perception argument presupposes that we can engage in discussions about the differences between the attitudes involved in remembering and imagining without talking about causal connections. However, the objection goes, the requirement for a causal connection is essential to characterizing the attitude of remembering, for part of what it means to say that a memory is accurate is that it is caused in an appropriate way by the event represented. So, even within a representationalist framework, the (dis)continuism debate ultimately boils down to the question of whether a causal connection is necessary for remembering.

This objection can be avoided by pointing out that, while it might be right in that reference to a causal connection is required to account for the accuracy conditions of memory, ${ }^{23}$ it is wrong in that such a reference is essential to characterize the attitude of remembering. In Section 3, I suggested that a causal connection is required to determine when the content of a memory representation is satisfied (see also Fernández, 2019). So, the requirement is not built into the attitude, but the content, of remembering. We can, therefore, make sense of the idea that reference to a causal connection is required to speak of the accuracy conditions of memory, without making that a fundamental aspect of the attitude of remembering.

It may be argued in response that, even if the argument developed in the paper does not require building a causal connection into the attitude of remembering, a view along these lines is not incoherent. So, one may be a representationalist and still maintain that the attitude of remembering is fundamentally different from the attitude of imagining because only the former requires a causal connection. In response, I want to acknowledge that this view is not logically incoherent and that it may provide a way for causalists and simulationists to avoid the analogy to perception argument. And indeed, a proposal along these lines has recently been advanced by Mahr \& Csibra (2018) and Mahr (2020). ${ }^{24}$ For proposals of this type to be successful, they need an argument showing why the requirement for a causal connection should be built into the attitude,

23 Although the simulationist will, of course, disagree with this claim.

24 For similar proposals, although they do not speak explicitly of attitudes, see Dokic (2001; 2014), Perner \& Ruffman (1995), Perrin et al. (2020). 
as opposed to the content, of remembering. ${ }^{25}$ This is, however, a controversial issue (Cf. Fernández, 2019) that I do not intend to resolve here. So, for my current purposes, I shall simply note that the question of whether reframing the debate over the (dis) continuity between memory and imagination in terms of attitudes will inevitably lead to discontinuism depends on resolving the more basic issue of whether we should build the requirement for a causal connection for remembering in its attitude or its content.

\subsection{The factivity of remembering}

A third objection appeals to the idea that remembering involves a factive attitude. Since a factive attitude requires its content to be accurate, it could be argued that a causal connection is essential to characterize the attitude of remembering. This would imply that one may be a representationalist and still maintain that the attitude of remembering is fundamentally different from the attitude of imagining - which is nonfactive- because only the former requires a causal connection.

While the issue of whether (episodic) remembering is factive is controversial, even if we accept that it is, it does not follow that a causal connection is essential to characterize the attitude of remembering. This objection assumes that a factive attitude requires the presence of a causal connection, but it is not clear why we should make this assumption. To see the point, consider an analogy to semantic or propositional memory, which is thought to involve a factive attitude (Fraise, 2015). It does not follow from this that characterizing the attitude of semantic remembering requires appealing to a causal connection. I can semantically remember that Paris is the capital of France even if that memory is not caused by the fact that Paris is the capital of France. All that is required is that this fact obtains in the world. A similar analogy can be made to knowledge. That knowledge involves a factive attitude does not imply that to know something, one needs to be causally connected in an appropriate way to what is known. In other words, one does not need to subscribe to a causal theory of knowledge to hold the view that knowledge is factive. Thus, even if remembering is taken to be factive, it does not follow that a causal connection is essential to characterize the attitude involved in it.

It may be replied that, even if the above is true, the notion that remembering is factive and imagining is not points to a fundamental difference between them. This brings us back to the first objection discussed above. If the analogy to perception argument is correct, then it follows that discontinuism is true, which threatens the neutrality of the argument. Two things can be said in response. First, as noted above, it is not uncontroversial that remembering is factive. As different authors have pointed out,

25 Mahr \& Csibra (2018, p. 3; see also Mahr, 2020) offer such an argument. 
there are good reasons to think that it is not. ${ }^{26}$ So, the truth of discontinuism ultimately depends on it being the case that remembering is factive. Second, that the factivity of remembering and the non-factivity of imagining is taken to be a potential reason for endorsing discontinuism only reinforces the conclusion of the analogy to perception argument. The issue of whether remembering and imagining are factive has to do with the nature of the attitudes involved in those mental states, and not with whether they require a causal connection. As noted in Section 3, the analogy to perception argument is neither an argument for nor against continuism and discontinuism. It establishes only that this dispute should be viewed as being about the nature of the attitudes involved in remembering and imagining. The fact that the factivity of remembering is said to support discontinuism only reinforces this idea.

\subsection{Representationalism without attitudes}

A fourth objection is that committing to the idea that memory and imagination are representational states does not require causalists and simulationists to endorse representationalism in the way that it is defined here. This point can be made in connection to the perception literature. While some have indeed defended the view according to which perception is a propositional attitude, others have explicitly denied this view in a representationalist framework. ${ }^{27}$ On views of this type, which we may call content representationalism, what characterizes a mental state as a perceptual state is the nature of its content, understood as its accuracy conditions. Likewise, one may argue that what characterizes a mental state as a memory/imagination is the nature of its content, understood as its accuracy conditions. Thus, if a causal connection is built into the content of memory and not into the content of imagination, it follows that there is a fundamental difference between them, which ultimately boils down to the presence (or absence) of a causal connection for remembering.

Endorsing content representationalism would allow causalists and simulationists to avoid the analogy to perception argument. The question is whether there are good reasons for them to do so. Let us start with causalists. As the painter case discussed previously illustrates, one important idea for causalism is that genuine remembering and apparent remembering, which includes merely imagining the past, can and often are phenomenologically indistinguishable. On a representationalist framework, where phenomenology supervenes on content, this would mean that some occurrences of imagining the past and some occurrences of remembering the past have contents of the same type, thus implying that they are mental state of the same kind. However, given

26 See Michaelian (2016b); De Brigard (2014a; 2017); Hazlett (2010).

27 See, e.g., Crane (2009); Siegel (2010); Schellenberg (2018). 
that causalists ultimately want to endorse discontinuism, this result is undesirable. So, causalism is not compatible with content representationalism.

Consider now simulationists. For continuism to follow from content representationalism, it must be the case that memory and imagination have contents of the same type. It is not clear, however, what the motivations for endorsing this claim are. The simulationist seems to agree that, despite being continuous, memory and imagination can represent things differently. For instance, the simulationist does not deny that sometimes memory represents events as being past and that sometimes imagination represents events as being future. But if that is the case, then there is a difference in the nature of the content of memory and imagination -namely, they represent time in a different way. So, unless simulationists can offer an account of the nature of the contents of memory and imagination that avoids these problems, which it is not clear they can, ${ }^{28}$ content representationalism is unlikely to be attractive for them.

In sum, it looks like that, given their commitments elsewhere, content representationalism is not a viable alternative for causalists and simulationists to resist the analogy to perception argument.

\subsection{Rejecting representationalism}

A fifth and final objection would be to deny representationalism. In doing so, one can reject (P2) from the analogy to perception argument, and as such, reject its conclusion. In response, it is fair to say that this an open possibility, and nothing in the discussion above establishes that (P2) is actually the case. However, as noted before, representationalism is widely accepted, particularly in the memory literature, so, while rejecting (P2) would be plausible, it would require substantial argumentation. Thus, the analogy to perception argument can be viewed as posing a dilemma for causalists and simulationists. That is, either it is true that memory and imagination are representational states, in which case the dispute over their (dis)continuity is not about the necessity of a causal connection for remembering, or it is the case that the dispute over (dis)continuity between memory and imagination is about the necessity of a causal connection for remembering, in which case it cannot be the case that memory and imagination are representational states. It is up to the causalist and the simulationist to choose which horn of the dilemma to endorse, and it may be that they will decide to endorse the second horn; however, should they do so, they will be faced with the difficult task of providing a non-representational account of memory and imagination.

28 See, e.g., De Brigard \& Gessell (2016) and Mahr (2020) for recent arguments that the contents of episodic representations are tenseless. 


\section{Conclusion}

In this paper, I argued that causalists and simulationists wrongly identify the issue of whether a causal connection is necessary for remembering as being central to their dispute over whether memory and imagination are (dis)continuous. I showed that, given their commitment to a representationalist approach to mental states, the question of whether memory and imagination are (dis)continuous should be viewed as a question about whether they involve the same or different attitudes towards contents. To secure this claim, I developed an argument in analogy to perception - what I called the analogy to perception argument- according to which, like in the case of perception, where given the truth of representationalism, requiring the presence of a causal connection for veridical experiences, but not for non-veridical experiences, only poses a nonfundamental difference between them, in the case of memory and imagination too, given the truth of representationalism, requiring the presence of a causal connection for remembering, but not for imagining, only poses a non-fundamental difference between. While the analogy to perception argument does not provide an answer to the question of whether memory and imagination are (dis)continuous, it establishes that, as long as representationalism is taken to be a starting point in this discussion, for there to be a fundamental difference between memory and imagination, it is required that the attitudes involved in each are different.

\section{References}

Addis, D. R. (2018). Are episodic memories special? on the sameness of remembered and imagined event simulation. Journal of the Royal Society of New Zealand, 48(2-3): 64-88. https:// doi.org/10.1080/03036758.2018.1439071

Addis, D. R. (2020). Mental time travel? A neurocognitive model of event simulation. Review of Philosophy and Psychology, 11, 233-259. https://doi.org/10.1007/s13164-020-00470-0

Addis, D. R., Wong, A. T. \& Schacter, D. L. (2007). Remembering the past and imagining the future: common and distinct neural substrates during event construction and elaboration. Neuropsychologia, 45(7), 1363-1377. https://doi.org/10.1016/j. neuropsychologia.2006.10.016

Bernecker, S. (2010). Memory: a philosophical study. Oxford University Press.

Burge, T. (1991). Vision and intentional content. In E. Lepore \& R. van Gulick (Eds.), John Searle and his critics (pp. 195-214). Blackwell.

Byrne, A. (2001). Intentionalism defended. Philosophical Review, 110(2), 199-240. https://doi. org/10.1215/00318108-110-2-199 
Byrne, A. (2009). Experience and content. The Philosophical Quarterly, 59(236), 429-451. https://doi.org/10.1111/j.1467-9213.2009.614.x

Crane, T. (2009). Is perception a propositional attitude? The Philosophical Quarterly, 59(236), 452-469. https://doi.org/10.1111/j.1467-9213.2008.608.x

Currie, G. \& Ravenscroft, I. (2002). Recreative minds: imagination in philosophy and psychology. Oxford University Press. https://doi.org/10.1093/acprof:0so/9780198238089.001.0001

De Brigard, F. (2014a). Is memory for remembering? Recollection as a form of episodic hypothetical thinking. Synthese, 191(2), 155-185. https://doi.org/10.1007/s11229-013-0247-7

De Brigard, F. (2014b). The nature of memory traces. Philosophy Compass, 9(6), 402-414. https://doi.org/10.1111/phc3.12133

De Brigard, F. (2017). Memory and imagination. In S. Bernecker \& K. Michaelian (Eds.), The Routledge Handbook of Philosophy of Memory (pp. 127-140). Routledge. https://doi.org/10.4324/9781315687315-11

De Brigard, F. \& Gessell, B. (2016). Time is not of the essence: Understanding the neural correlates of mental time travel. In K. Michaelian, S. B. Klein \& K. K. Szpunar (Eds.), Seeing the future: theoretical perspectives on future-oriented mental time travel (pp. 153-179). Oxford University Press. https://doi.org/10.1093/acprof:0so/9780190241537.003.0008

Debus, D. (2008). Experiencing the past: a relational account of recollective memory. Dialectica, 62(4). 405-432. https://doi.org/10.1111/j.1746-8361.2008.01165.x

Debus, D. (2010). Accounting for epistemic relevance: a new problem for the causal theory of memory. American Philosophical Quarterly, 47(1), 17-29.

Debus, D. (2014). 'Mental time travel': remembering the past, imagining the future, and the particularity of events. Review of Philosophy and Psychology, 5(3), 333-350. https://doi.org/10.1007/s13164-014-0182-7

Dokic, J. (2001). Is memory purely preservative? In C. Hoerl \& T. McCormack (Eds.), Time and memory: issues in philosophy and psychology (pp. 213-232). Oxford University Press.

Dokic, J. (2014). Feeling the past: a two-tiered account of episodic memory. Review of Philosophy and Psychology, 5(3), 413-426. https://doi.org/10.1007/s13164-014-0183-6

Fernández, J. (2018). The functional character of memory. In K. Michaelian, D. Debus \& D. Perrin (Eds.), New Directions in the Philosophy of Memory (pp. 52-72). Routledge. https://doi.org/10.4324/9781315159591-4

Fernández, J. (2019). Memory: a self-Referential account. Oxford University Press. https://doi.org/10.1093/0so/9780190073008.001.0001

Fodor, J. (1978). Propositional attitudes. The Monist, 61(4), 501-523. https://doi.org/10.5840/ monist197861444

Frise, M. (2015). Epistemology of memory. The Internet Encyclopedia of Philosophy. https://iep.utm.edu/ 
Hazlett, A. (2010). The myth of factive verbs. Philosophy and Phenomenological Research, 80(3),497-522. https://doi.org/10.1111/j.1933-1592.2010.00338.x

Hopkins, R. (2018). Imagining the past: on the nature of episodic memory. In F. MacPherson \& F. Dorsch (Ed.), Perceptual Imagination and Perceptual Memory. Oxford University Press.

Hutto, D. D. \& Myin, E. (2017). Evolving enactivism: basic minds meet content. MIT Press. https:// doi.org/10.7551/mitpress/9780262036115.001.0001

Langland-Hassan, P. (2015). Imaginative attitudes. Philosophy and Phenomenological Research, 90(3), 664-686. https://doi.org/10.1111/phpr.12115

Langland-Hassan, P. (2021). What sort of imagining might remembering be? Journal of the American Philosophical Association, 7(2), 231-51.

Liao, S.-Y. \& Gendler, T. (2019). Imagination. In E. N. Zalta (Ed.), The Stanford Encyclopedia of Philosophy. Metaphysics Research Lab, Stanford University.

Mahr, J. B. (2020). The dimensions of episodic simulation. Cognition, 196, 104085. https://doi. org/10.1016/j.cognition.2019.104085

Mahr, J. B. \& Csibra, G. (2018). Why do we remember? The communicative function of episodic memory. Behavioral and Brain Sciences, 41. https://doi.org/10.1017/S0140525X17000012

Martin, C. B. \& Deutscher, M. (1966). Remembering. Philosophical Review, 75(2), 161-96. https:// doi.org/10.2307/2183082

Michaelian, K. (2011). Generative memory. Philosophical Psychology, 24(3), 323-342. https:// doi.org/10.1080/09515089.2011.559623

Michaelian, K. (2016a). Against discontinuism: mental time travel and our knowledge of past and future events. In K. Michaelian, S. B. Klein \& K. K. Szpunar (Eds.), Seeing the future: theoretical perspectives on future-oriented mental time travel (pp. 62-92). Oxford University Press. https://doi.org/10.1093/acprof:oso/9780190241537.003.0004

Michaelian, K. (2016b). Mental time travel: episodic memory and our knowledge of the personal past. MIT Press. https://doi.org/10.7551/mitpress/10591.001.0001

Michaelian, K., Perrin, D. \& Sant'Anna, A. (2020). Continuities and discontinuities between imagination and memory: the view from philosophy. In A. Abraham (Ed.), The Cambridge handbook of imagination. Cambridge University Press. https://doi. org/10.1017/9781108580298.019

Michaelian, K. \& Robins, S. K. (2018). Beyond the causal theory? Fifty years after Martin and Deutscher. In K. Michaelian, D. Debus, \& D. Perrin (Ed.), New directions in the philosophy of memory (pp. 13-32). Routledge. https://doi.org/10.4324/9781315159591-2

Munro, D. (2020). Remembering the past and imagining the actual. Review of Philosophy and Psychology. Online ahead of print. https://doi.org/10.1007/s13164-020-00499-1

Nanay, B. (2015). Perceptual content and the content of mental imagery. Philosophical Studies, 172(7), 1723-1736. https://doi.org/10.1007/s11098-014-0392-y 
Perner, J. \& Ruffman, T. (1995). Episodic memory and autonoetic aonciousness: developmental evidence and a theory of childhood amnesia. Journal of Experimental Child Psychology, 59, 516-548. https://doi.org/10.1006/jecp.1995.1024

Perrin, D. (2016). Asymmetries in subjective time. In K. Michaelian, S. B. Klein \& K. K Szpunar, (Eds.), Seeing the future: theoretical perspectives on future-oriented mental time travel (pp. 39-61). Oxford University Press. https://doi.org/10.1093/acprof:0 so/9780190241537.003.0003

Perrin, D. \& Michaelian, K. (2017). Memory as mental time travel. In S. Bernecker \& K. Michaelian (Eds.), The Routledge handbook of philosophy of memory (pp. 228-239). Routledge. https://doi.org/10.4324/9781315687315-19

Perrin, D., Michaelian, K. \& Sant'Anna, A. (2020). The phenomenology of remembering is an epistemic feeling. Frontiers in Psychology, 11, 1531. https://doi.org/10.3389/ fpsyg.2020.01531

Robins, S. K. (2016). Representing the past: memory traces and the causal theory of memory. Philosophical Studies, 173(11), 2993-3013. https://doi.org/10.1007/s11098-016-0647-x

Robins, S. K. (2017). Memory traces. In S. Bernecker \& K. Michaelian (Eds.), The Routledge handbook of philosophy of memory (pp. 76-87). Routledge. https://doi. org/10.4324/9781315687315-7

Robins, S. K. (2020). Defending discontinuism, naturally. Review of Philosophy and Psychology, 11, 469-486. https://doi.org/10.1007/s13164-020-00462-0

Sant'Anna, A. (2020). The hybrid contents of memory. Synthese 197, 1263-1290. https://doi. org/10.1007/s11229-018-1753-4

Sant'Anna, A., Michaelian, D. \& Perrin, D. (2020). Editorial: memory as mental time travel. Review of Philosophy and Psychology, 11, 223-232. https://doi.org/10.1007/s13164-020-00484-8

Schacter, D. L., Addis, D. R. \& Buckner, R. L. (2007). Remembering the past to imagine the future: the prospective brain. Nature Reviews Neuroscience, 8(9), 657-661. https://doi. org/10.1038/nrn2213

Schacter, D. L., Addis, D. R., Hassabis, D., Martin, V. C., Spreng, R. N. \& Szpunar, K. K. (2012). The future of memory: remembering, imagining, and the brain. Neuron, 76(4), 677-694. https://doi.org/10.1016/j.neuron.2012.11.001

Schellenberg, S. (2010). The particularity and phenomenology of perceptual experience. Philosophical Studies, 149(1), 19-48. https://doi.org/10.1007/s11098-010-9540-1

Schellenberg, S. (2018). The unity of perception: content, consciousness, evidence. Oxford University Press. https://doi.org/10.1093/oso/9780198827702.001.0001

Searle, J. R. (1983). Intentionality: an essay in the philosophy of mind. Cambridge University Press. https://doi.org/10.1017/CBO9781139173452 
Shanton, K. \& Goldman, A. (2010). Simulation theory. Wiley Interdisciplinary Reviews, Cognitive Science, 1(4), 527-538. https://doi.org/10.1002/wcs.33

Siegel, S. (2010). The contents of visual experiences. Oxford University Press. https://doi. org/10.1093/acprof:0so/9780195305296.003.0002

Soteriou, M. (2000). The particularity of visual experience. European Journal of Philosophy, 8(2), 173-89. https://doi.org/10.1111/1468-0378.00107

Sutton, J. (1998). Philosophy and memory traces: Descartes to connectionism. Cambridge University Press. https://doi.org/10.1111/1467-8721.ep10770899

Tulving, E. (1993). What is episodic memory? Current Directions in Psychological Science, 2(3), 67-70. https://doi.org/10.1146/annurev.psych.53.100901.135114

Tulving, E. (2002). Episodic memory: from mind to brain. Annual Review of Psychology, 53(1), 1-25. https://doi.org/10.1093/acprof:0so/9780195161564.003.0001

Tulving, E. (2005). Episodic memory and autonoesis: uniquely human? In H. S. Terrace \& J. Metcalfe (Eds.), The missing link in cognition: origins of self-reflective consciousness (pp. 3-56). Oxford University Press. https://doi.org/10.7551/mitpress/2110.001.0001

Tye, M. (2000). Consciousness, color, and content. MIT Pres.

Van Leeuwen, N. (2013). The meanings of "imagine", part 1: constructive imagining. Philosophy Compass, 8, 220-230. https://doi.org/10.1111/j.1747-9991.2012.00508.x

Werning, M. (2020). Predicting the past from minimal traces: episodic memory and its distinction from imagination and preservation. Review of philosophy and psychology, 11, 301-333. https://doi.org/10.1007/s13164-020-00471-z 